\title{
Ischemic preconditioning in the rat hippocampus increases antioxidant activities but does not affect the level of hydroxyl radicals during subsequent severe ischemia
}

\author{
Yun-Sik Choi ${ }^{1}$, Kyung-Ok Cho ${ }^{1,2}$, \\ Eun-Jeong Kim ${ }^{1}$, Ki-Wug Sung ${ }^{1,2}$ \\ and Seong Yun $\mathrm{Kim}^{1,2,3}$ \\ ${ }^{1}$ Department of Pharmacology \\ ${ }^{2}$ Cell Death Disease Research Center of MRC \\ College of Medicine, The Catholic University of Korea \\ Seoul 137-701, Korea \\ ${ }^{3}$ Corresponding author: Tel, 82-2-590-1205; \\ Fax, 82-2-536-2485; E-mail, syk@ catholic.ac.kr
}

Accepted 5 July 2007

Abbreviations: 2,3-DHBA, 2,3-dihydroxybenzoic acid; 2,5-DHBA, 2,5-dihydroxybenzoic acid; Cu/Zn-SOD, copper/zinc superoxide dismutase; GPx, glutathione peroxidase; Mn-SOD, manganesesuperoxide dismutase

\begin{abstract}
Several studies have demonstrated that ischemic preconditioning increases superoxide dismutase activity, but it is unclear how ischemic preconditioning affects events downstream of hydrogen peroxide production during subsequent severe ischemia and reperfusion in the hippocampus. To answer this question, we investigated whether ischemic preconditioning in the hippocampal CA1 region increases the activities of antioxidant enzymes glutathione peroxidase and catalase, resulting in a decrease in the level of hydroxyl radicals during subsequent severe ischemia-reperfusion. Transient forebrain ischemia was induced by four-vessel occlusion in rats. Ischemic preconditioning for $3 \mathrm{~min}$ or a sham operation was performed and a 15-min severe ischemia was induced three days later. Ischemic preconditioning preserved the CA1 hippocampal neurons following severe ischemia. The concentration of 2,3-dihydroxybenzoic acid, an indicator of hydroxyl radical, was measured using in vivo microdialysis technique combined with HPLC. The ischemia-induced increase in the ratio of 2,3-dihydroxybenzoic acid concentration relative to baseline did not differ significantly between preconditioned and control groups. On the other hand, activities of the antioxidant enzymes glu-
\end{abstract}

tathione peroxidase-1 and catalase were significantly increased at 3 days after ischemic preconditioning in the hippocampus. Our results suggest that, in preconditioned rats, while hydrogen peroxide is generated from severe ischemia, the activity of catalase and glutathione peroxidase- 1 is correspondingly increased to eliminate the excessive hydrogen peroxide. However, our results show that the enhanced activity of these antioxidant enzymes in preconditioned rats is not sufficient to decrease hydroxyl radical levels during subsequent severe ischemia-reperfusion.

Keywords: brain ischemia; catalase; glutathione peroxidase; hippocampus; hydroxyl radical; ischemic preconditioning

\section{Introduction}

Transient forebrain ischemia induces delayed neuronal death in the hippocampal CA1 region. Oxygen free radicals have been suggested to play a significant role in this neuronal death (Piantadosi and Zhang, 1996; Yamamoto et al., 1997; Kim et al., 1999, 2006; Song et al., 2007). It is particularly interesting that superoxide generation increases during cerebral ischemia-reperfusion (Chan et al., 1998; Sugawara et al., 2005). Superoxide reportedly induces damage in the endoplasmic reticulum (Hayashi et al., 2005). Also, superoxide can form another toxic radical, peroxynitrite, through a reaction with nitric oxide which is specifically accumulated in regions that are vulnerable to ischemic insults (Hicks et al., 1999; Calapai et al., 2000; Choi et al., 2004). Overexpression of copper/zinc superoxide dismutase (Cu/Zn-SOD) minimizes superoxide toxicity, resulting in reduction of cell death (Sugawara et al., 2002). Thus, understanding radical generation and subsequent toxicity can lead to therapeutic tools to prevent brain injury including ischemic insult.

Kitagawa et al. (1990) first showed that short periods of ischemia (ischemic preconditioning) protect vulnerable neurons against subsequent ischemic injury. There is much evidence that ischemic preconditioning increases the expression level of SOD, an enzyme that converts superoxide into 
hydrogen peroxide (Kato et al., 1995; Wada et al., 2001). Increased activity of SOD results in a reduction in both superoxide and peroxynitrite toxicity. Downregulation of $\mathrm{Cu} / \mathrm{Zn}-\mathrm{SOD}$ increases cell death via peroxynitrite formation (Troy et al., 1996). In addition, overexpression of Cu/Zn-SOD minimizes superoxide toxicity, resulting in reduction of cell death (Sugawara et al., 2002). It is possible that increased expression of SOD may result in the accumulation of hydrogen peroxide. After severe ischemia-reperfusion in preconditioned rats, this SOD-induced increase in hydrogen peroxide could cause increased production of hydroxyl radical which has been known as one of the most toxic free radicals both in vivo and in vitro excitotoxic conditions including ischemia (Christensen et al., 1994; Zhang and Piantadosi, 1994; Kil et al., 1996; Yamamoto et al., 1997). Hydroxyl radical may damage cells through the development of DNA fragmentation and lipid peroxidation (Gutteridge, 1984; Tsang et al., 1996; Rollet-Labelle et al., 1998). Thus, it is critical to understand how ischemic preconditioning affects events downstream of hydrogen peroxide production.

In the present study, we investigated whether ischemic preconditioning modulates hydroxyl radical levels during severe ischemia and reperfusion, and examined the activities of antioxidant enzymes catalase and glutathione peroxidase (GPx)-1 in the rat hippocampus.

\section{Materials and Methods}

\section{Time-schedule of forebrain ischemia}

Age-matched, adult male Sprague-Dawley rats (250-300 g, Koatech, Pyeongtaek, Korea) were used. The time-schedule of this experiment was summarized in Figure 1. Severe ischemia or ischemic preconditioning was induced by four-vessel occlusion according to Pulsinelli and Brierley (1979) with minor modification (Lee et al., 2002). In brief, rats were anaesthetized with chloral hydrate (400 mg/kg, i.p.) and the vertebral arteries were electrocauterized (Day 1). After 24 h (Day 2), ischemic preconditioning was induced by occlusion of both common carotid arteries for $3 \mathrm{~min}$. As a control group for ischemic preconditioning, animals were subjected to the same anesthesia and surgical procedures, yet with a sham manipulation rather than artery occlusion. Three days later (Day $5)$, severe ischemia was induced for $15 \mathrm{~min}$ in all rats of both groups. Body temperature was maintained at $37.5 \pm 0.3^{\circ} \mathrm{C}$ with a heat lamp during and after the global ischemia. All experimental procedures performed on the animals were conducted with the approval of the Ethics Committee of the Catholic University of Korea, and were in accordance with the National Institutes of Health Guide for the Care and Use of Laboratory Animals (NIH Publication No. 80-23, revised 1996).

\section{In vivo microdialysis}

In each group (preconditioned and sham), six rats were used. For the determination of hydroxyl radical levels, an in vivo microdialysis technique was used. Two days after ischemic preconditioning or sham manipulation (Day 4), a guide cannula was stereotaxically implanted (AP: $-4.1 \mathrm{~mm}, \mathrm{ML}$ : $-2.8 \mathrm{~mm}$, DV: $-0.9 \mathrm{~mm}$ ) using the atlas of Paxinos and Waston (1998) and fixed with dental cement on the skull surface. To locate the microdialysis probe along the pyramidal cell layer of hippocampal CA1, the guide cannula was implanted with

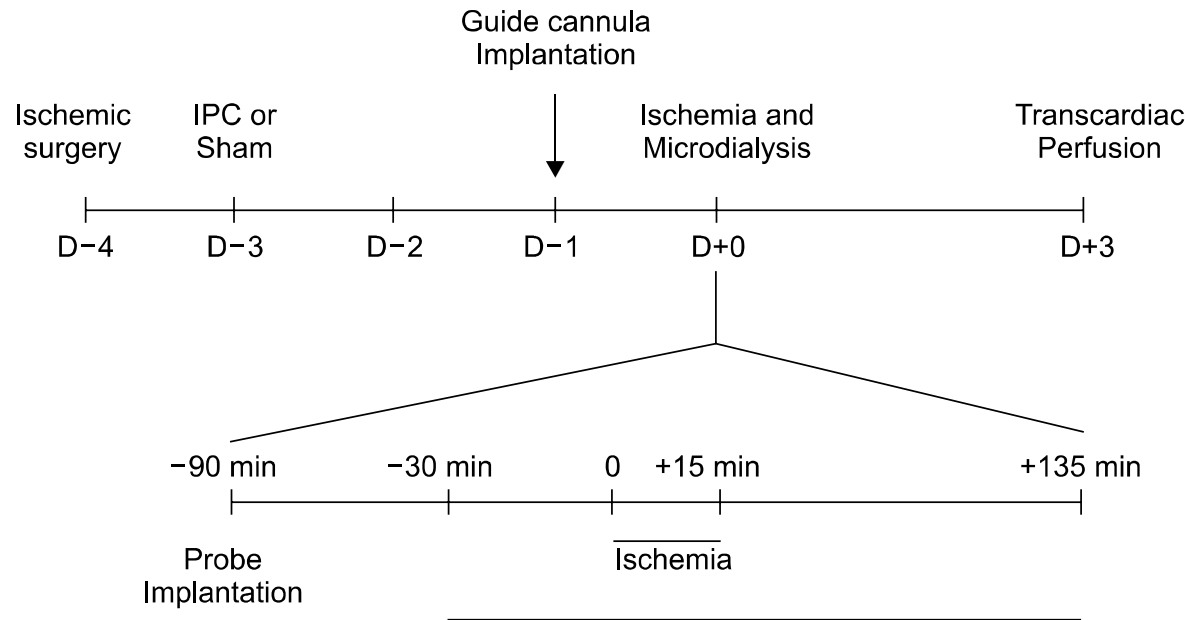

Microdialysis
Figure 1. Summary of experimental protocol. Ischemic preconditioning (IPC) was induced for $3 \mathrm{~min}$. Three days later severe ischemia was induced for $15 \mathrm{~min}$. A microdialysis probe was implanted 90 min before severe ischemia induction and Ringer solution containing salicylate was perfused. After stabilizing baseline condition for $60 \mathrm{~min}$, perfusate was collected every $15 \mathrm{~min}$ until $2 \mathrm{~h}$ after reperfusion. In a second group of rats, hippocampi were harvested at time $D+$ 0 to measure the activities and expression levels of antioxidant enzymes prior to subsequent ischemia-reperfusion. 
a $40^{\circ}$ gradient from lateral to medial side. After 24 h (Day 5), a microdialysis probe (diameter: 240 $\mu \mathrm{m}$, length: $2 \mathrm{~mm}, \mathrm{CMA} / 11$, Carnegie Medicine, Stockholm, Sweden) was placed inside the guide cannula $90 \mathrm{~min}$ before severe ischemia induction and perfused with Ringer solution $(\mathrm{NaCl} 148.2 \mathrm{mM}$, $\mathrm{KCl} 4 \mathrm{mM}, \mathrm{CaCl}_{2} 2.3 \mathrm{mM}, \mathrm{pH} 7.0$ ) containing $5 \mathrm{mM}$ sodium salicylate (Sigma, St Louis, MO) at a rate of $2 \mu \mathrm{l} / \mathrm{min}$. One hour of recovery time was allowed following the implantation of probe before basal values were monitored for $30 \mathrm{~min}$. From $30 \mathrm{~min}$ before severe ischemia induction until $120 \mathrm{~min}$ after reperfusion, microdialysates were collected every $15 \mathrm{~min}$ into eppendorf tubes containing $30 \mu \mathrm{l}$ of $0.1 \mathrm{mM}$ perchloric acid and frozen at $-70^{\circ} \mathrm{C}$ until use (Obata, 1997).

\section{HPLC}

To measure the concentration of 2,3-dihydroxybenzoic acid (DHBA) as an indicator of hydroxyl radical, HPLC system with an electrochemical detector was used. The system consisted of a Waters 510 pump (Waters, Milford, MA), autosampler (Spark Holland, Emmen, Netherlands), DHBA250 column $(5 \mu \mathrm{m}, 250 \times 3.0 \mathrm{~mm}$, ESA, Chelmsford, MA), electrochemical detector (M5200A, ESA), dual analytical cell (M5011, ESA), guard cell (M5020, ESA) and integrator (Spectra-Physics analytical, Mountain View, CA). The detector potentials were set at $+250 \mathrm{mV}(\mathrm{E} 1),+750 \mathrm{mV}(\mathrm{E} 2)$ and $+775 \mathrm{mV}$ (guard cell). The mobile phase contained $5 \%$ isopropyl alcohol, $15 \%$ methanol, 50 $\mathrm{mM}$ sodium acetate and $50 \mathrm{mM}$ citric acid, and was adjusted to a final $\mathrm{pH}$ of 2.5 with $85 \%$ phosphoric acid. The eluent was delivered with a flow rate of $0.5 \mathrm{ml} / \mathrm{min}$.

\section{Tissue processing}

Three days after severe ischemia and reperfusion (Day 8), rats were deeply anesthetized with chloral hydrate (600 mg/kg; Merck, Darmstadt, Germany) and perfused with cold saline followed by $4 \%$ paraformaldehyde in $0.1 \mathrm{M}$ phosphate buffer (PB, $\mathrm{pH}$ 7.4). The brain was then removed and postfixed in the same fixative for $4 \mathrm{~h}$. After cryoprotection with $30 \%$ sucrose in $0.1 \mathrm{M} \mathrm{PB}, 25 \mu \mathrm{m}$ sections were cut using a cryostat (Beckman, Fullerton, CA). To identify cell viability, tissues were stained with cresyl violet. In brief, sections were mounted onto a gelatin-coated slide and dried. After rehydration in 95, 90, 80 and $70 \%$ ethanol and distilled water for $3 \mathrm{~min}$ each, sections were stained with $0.3 \%$ cresyl violet solution. After destaining in $95 \%$ ethanol containing $0.1 \%$ acetic acid glacial, sections were dehydrated and covered with permount.

\section{Enzyme activity test}

For catalase or GPx activity determinations, rats were killed 3 days after ischemic preconditioning or sham manipulation. For each group (preconditioned and sham), six rats were used. Immediately after decapitation, the hippocampus was removed on an ice-chilled plate, weighed and stored at $-70^{\circ} \mathrm{C}$. Tissues were ultrasonically homogenized in $1 \mathrm{ml}$ of $0.05 \mathrm{M}$ phosphate buffer, $\mathrm{pH} 7.0$ and the protein concentration was measured. We assayed catalase activity in the hippocampus with a kit that uses $\mathrm{H}_{2} \mathrm{O}_{2}$ as a substrate (Sigma). The reaction mixture containing homogenate was incubated with $0.2 \mathrm{M} \mathrm{H}_{2} \mathrm{O}_{2}$ at $25^{\circ} \mathrm{C}$ for $1 \mathrm{~min}$ and the reaction was stopped by adding stop solution containing sodium azide. After mixing with color reagent containing $0.25 \mathrm{mM} 4$-aminoantipyrine and 2 mM 3,5-dichloro-2-hydroxybenzenesulfonic acid, we measured absorbance at $520 \mathrm{~nm}$. We assayed GPx activity in the hippocampus with a kit using tert-butyl hydroperoxide as substrate (Sigma). The reaction mixture containing homogenate was incubated with assay reagent containing $\mathrm{NADPH}$ and $30 \mathrm{mM}$ tert-butyl hydroperoxide solution for 30 $\mathrm{s}$ and absorbance was measured at $340 \mathrm{~nm}$.

\section{Western blot analysis}

Ten microgram of hippocampus homogenate was mixed with an equal volume of sample buffer. The samples were heated for $5 \mathrm{~min}$ at $95^{\circ} \mathrm{C}$. The proteins were analyzed by electrophoresis on 8 or $12 \%$ polyacrylamide gels for catalase or GPxs, respectively. Proteins were electrophoretically transferred from the SDS-polyacrylamide gel to nitrocellulose membranes (Bio-Rad, Hercules, CA). The membrane was blocked in $1 \%$ casein for $1 \mathrm{~h}$. The blot was then incubated with rabbit anti-GPx-1 (Labfrontier, Seoul, Korea) or mouse anti-catalase antibodies (Sigma) overnight at $4^{\circ} \mathrm{C}$. Each antibody was identified with goat-anti rabbit IgG or goat-anti mouse $\lg G$, conjugated with HRP, and incubated for $1 \mathrm{~h}$ at room temperature. The signal was visualized by using Renaissance chemiluminescent HRP substrate (PerkinElmer Life Sciences, Wellesley, MA). As a control for equal loading of protein across the gel, membranes were stripped and probed for $\beta$-tubulin (Sigma) expression using the same method. 

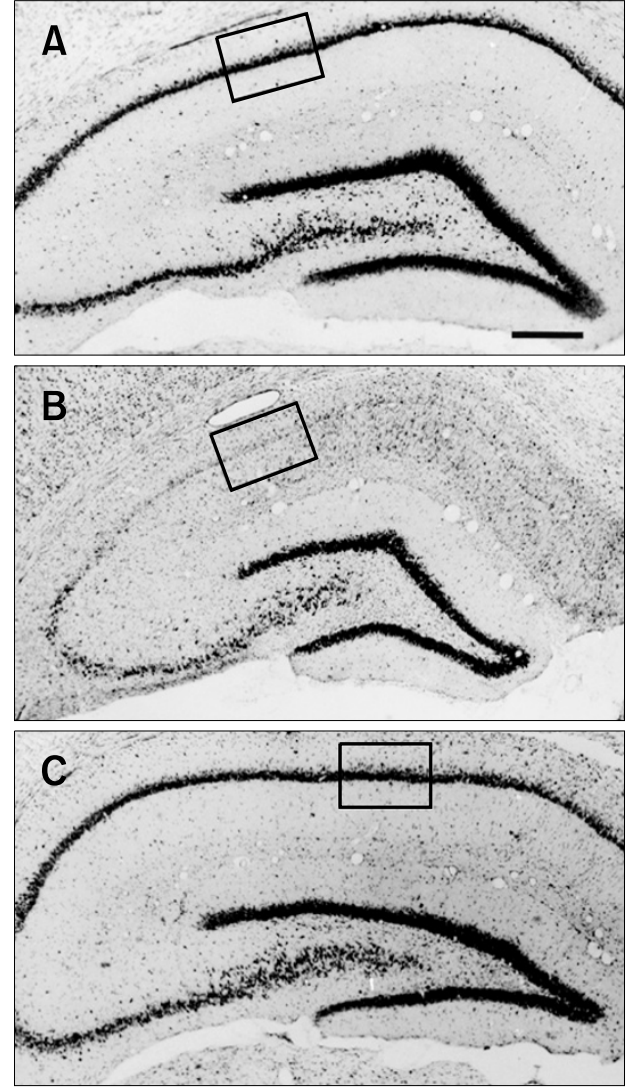
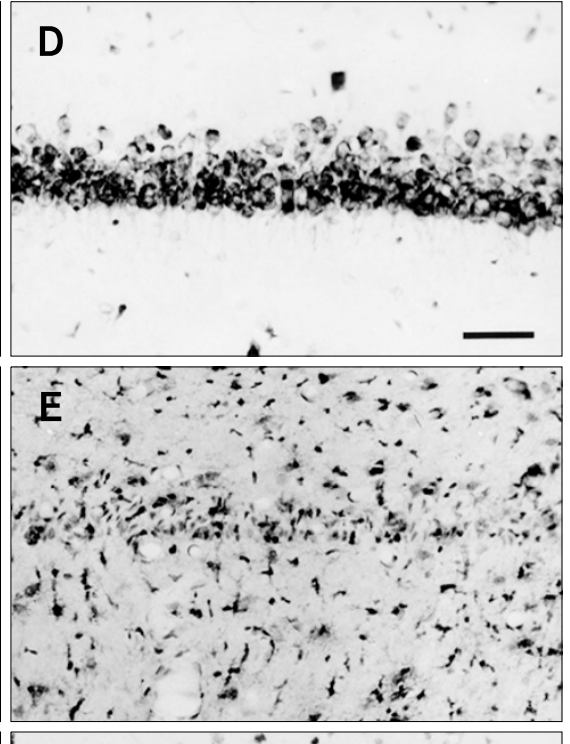

$F$

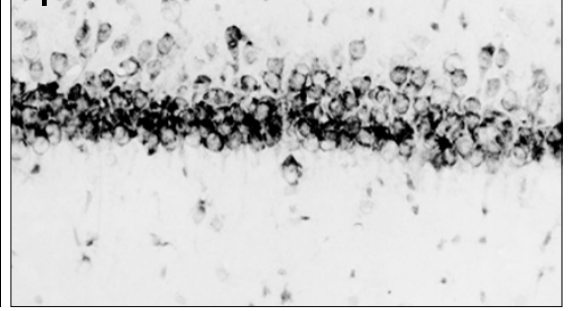

Figure 2. Histopathological observations of the hippocampus. Control $(A, B)$ three days after forebrain ischemia for $15 \mathrm{~min}$ in the rat without $(C, D)$ and with $(E, F)$ ischemic preconditioning. Preconditioning was induced by 4-vessel occlusion for $3 \mathrm{~min}$ followed by reperfusion for 3 days. Hippocampal CA1 neurons were destroyed in the rat without preconditioning $(C, D)$, but preserved with preconditioning $(E, F)$. Scale bars, 1,500 $\mu \mathrm{m}$ for $\mathrm{A}-\mathrm{C} ; 400 \mu \mathrm{m}$ for D-F.

\section{Statistics}

Statistical analysis was done using Student's $t$-test, and significance was accepted at $P<0.05$.

\section{Results}

\section{Identification of ischemic tolerance in the hippocampal CA1 region}

The experimental time-course is summarized in Figure 1. At three days after severe ischemia, rats that did not undergo ischemic preconditioning had few surviving pyramidal neurons in the CA1 region of the hippocampus compared to the control group (Figure $2 \mathrm{~A}$ and $2 \mathrm{~B}$ ). However, ischemic preconditioning in this experimental system successfully prevented neuronal loss induced by severe ischemia (Figure $2 \mathrm{C}$ ).

\section{The lack of effect of ischemic preconditioning on hydroxyl radical levels in the hippocampal CA1 area after severe ischemia}

Representative chromatograms of 2,3- and 2,5DHBA are shown in Figure $3 \mathrm{~A}$ and 3B. Figure $3 \mathrm{~A}$ shows a chromatogram from a standard solution containing $25 \mathrm{nM}$ 2,3- and 2,5-DHBA and Figure $3 \mathrm{~B}$ shows the chromatogram from in vivo microdialysate containing $31.1 \mathrm{nM} 2,3-\mathrm{DHBA}$ during the ischemic period. Previous reports showed that 2,5-DHBA can be formed in vivo by the action of cytochrome P450 (Ingelman-Sundberg et al., 1991). Therefore, we chose 2,3-DHBA as an indicator of hydroxyl radical in the hippocampus. Figure $3 \mathrm{C}$ shows the concentration of 2,3-DHBA in microdialysate from $30 \mathrm{~min}$ before ischemia to $120 \mathrm{~min}$ after reperfusion. The basal concentration of 2,3DHBA was calculated as the mean concentration of 2,3-DHBA in two microdialysates obtained during the pre-ischemic period. The basal concentrations of 2,3-DHBA were $30.1 \pm 7.7 \mathrm{nM}$ and $28.6 \pm 8.1 \mathrm{nM}$ in control and preconditioned groups, respectively. A transient forebrain ischemia significantly increased 2,3-DHBA production in both groups $(56.5 \pm 12.2 \%$ and $54.8 \pm 8.9 \%$ in control and preconditioned groups, respectively). These data show that ischemic preconditioning does not have a significant effect on hydroxyl radical levels in the hippocampus during subsequent severe ischemia and early reperfusion. 
A

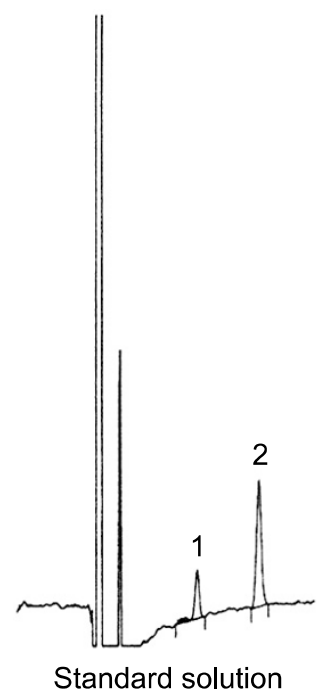

B

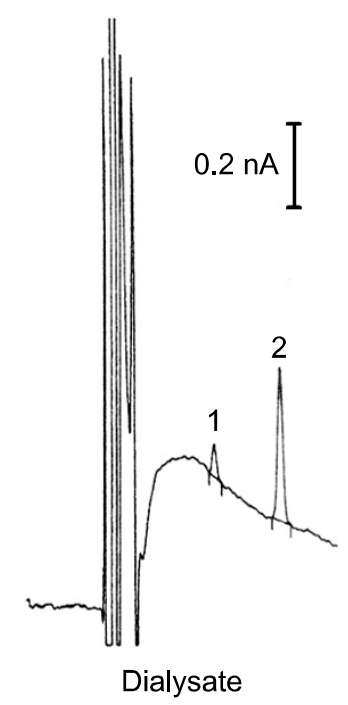

C

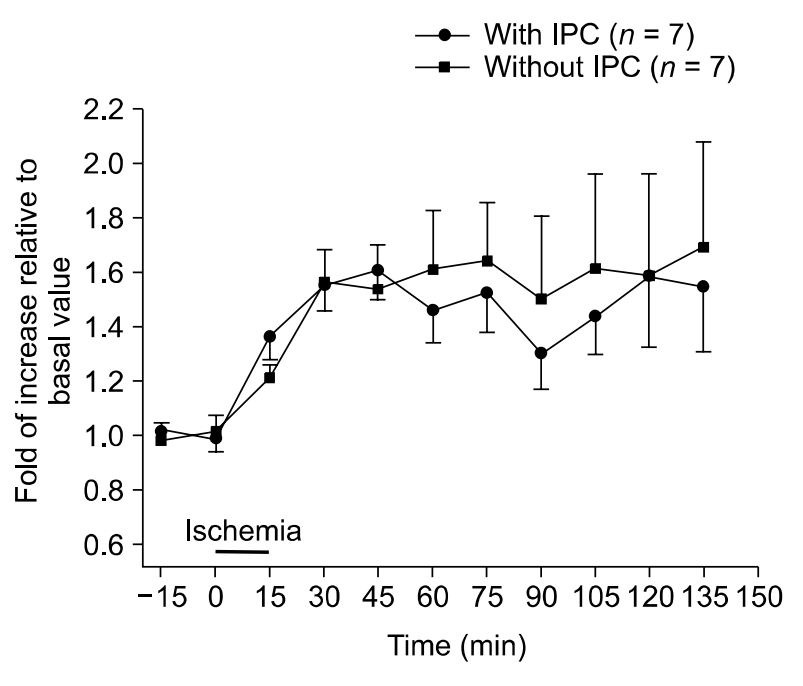

Figure 3. Effects of ischemic preconditioning on hydroxyl radical levels during severe ischemia-reperfusion in the rat hippocampus. (A-B) Representative HPLC chromatograms. Each chromatogram indicates the result of standard solution (A, 2,3-DHBA of $25 \mathrm{nM}$ ) and a dialysate (B, 2,3-DHBA of $31.1 \mathrm{nM})$ from the hippocampal CA1 area during the ischemic period. 1 and 2 represent 2,5-DHBA and 2,3-DHBA, respectively. (C) In both control and preconditioned groups, extracellular 2,3-DHBA concentrations were increased during ischemic and reperfusion periods. Data were obtained from 6 rats in each group and presented as mean \pm SEM.

A

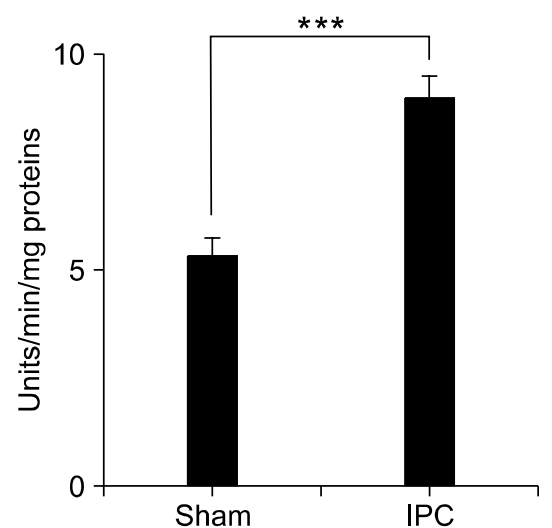

B

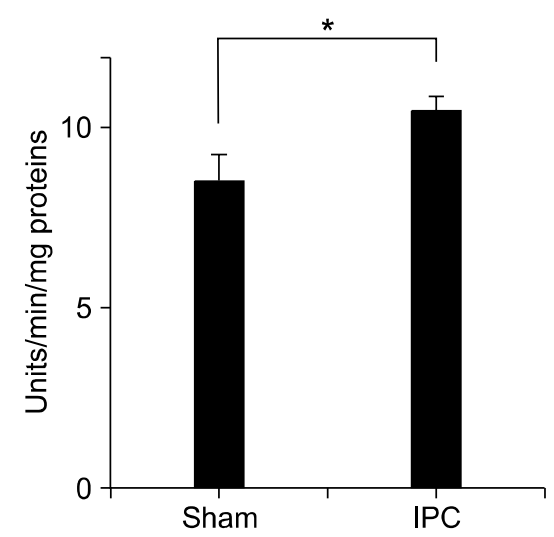

Figure 4. Enzymatic activities of catalase (A) and glutathione peroxidase-1 (GPx-1, B) in the hippocampus after ischemic preconditioning. Hippocampal tissue was isolated 3 days after ischemic preconditioning or sham manipulation and the activity of each enzyme was measured. (A) Ischemic preconditioning for 3 min significantly increased enzymatic activity of catalase in the hippocampus at 3 days post-treatment. One unit of catalase decomposes $1.0 \mu \mathrm{mol}$ of hydrogen peroxide into oxygen and water per minute at pH 7.0 at $25^{\circ} \mathrm{C}$ at a substrate concentration of $10 \mathrm{mM}$ hydrogen peroxide. (B) Ischemic preconditioning for 3 min significantly increased enzymatic activity of GPx-1 in the hippocampus at 3 days post-treatment. One unit of GPx-1 catalyzes the formation of $1.0 \mathrm{mmol}$ of NADP ${ }^{+}$from NADPH per minute at $\mathrm{pH} 8.0$ at $25^{\circ} \mathrm{C}$. Values are presented as mean \pm SEM. Six animals were used in each group (pre-conditioned and sham). ${ }^{*} P<0.05,{ }^{* * *} P<$ 0.001 compared to sham-manipulated rats.

\section{Determination of antioxidant enzyme activity after ischemic preconditioning}

As mentioned above, increased expression of manganese-SOD (Mn-SOD) by ischemic precondi- tioning could increase production of hydrogen peroxide. Therefore, we asked whether ischemic preconditioning increases the activity of enzymes that convert hydrogen peroxide into water molecules. To examine this, we examined the activity of 


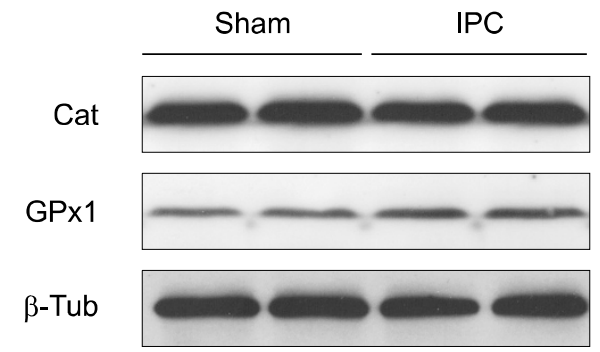

Figure 5. Western blot analysis of catalase and glutathione peroxidase-1 in the rat hippocampus 3 days after ischemic preconditioning or sham manipulation. Cat, catalase; GPx1, glutathione peroxidase-1; IPC, ischemic preconditioning; $\beta$-Tub, $\beta$-tubulin.

catalase and GPx-1 at 3 days after either ischemic preconditioning or sham manipulation. As shown in Figure 4, both enzyme activities were significantly increased following ischemic preconditioning (increases of $66.9 \%$ and $22.6 \%$ for catalase and GPX-1, respectively). These data suggest that ischemic preconditioning significantly increases the activity of antioxidant enzymes that convert hydrogen peroxide into water molecules.

\section{Expression of antioxidant enzymes after ischemic preconditioning}

To examine whether the activity of antioxidant enzymes such as catalase and GPx-1 is associated with their expression, we did western blot analysis. We harvested hippocampal tissue at 3 days after either ischemic preconditioning or sham manipulation. We found no significant difference in enzyme expression between the two groups (Figure 5).

\section{Discussion}

The results of the present study show that 1) ischemic preconditioning does not have a significant effect on production of 2,3-DHBA, an indicator of hydroxyl radical, in the hippocampal CA1 region during subsequent severe ischemia and early period of reperfusion, and 2) ischemic preconditioning enhances the activity of $\mathrm{H}_{2} \mathrm{O}_{2}$ degrading enzymes such as GPx-1 and catalase.

Brain ischemia results in a significant increase in the production of superoxide anions (Chan et al., 1998; Sugawara et al., 2005), which are converted into hydrogen peroxide by SOD. In turn, hydrogen peroxide is broken down into either hydroxyl radical via the Fenton reaction, or into water molecules via the activity of catalse or GPx. Increased generation of hydroxyl radicals could play a pivotal role in the delayed neuronal death seen after ischemic insult. For example, the concentration of hydroxyl radical increases in the hippocampus following ischemia-reperfusion injury (Christensen et al., 1994; Zhang and Piantadosi, 1994), and the inhibition of hydroxyl radical generation prevents the delayed neuronal death (Kil et al., 1996; Yamamoto et al., 1997). In the present study, the production of 2,3-DHBA significantly increased in the hippocampal CA1 region during severe ischemia and reperfusion, in accordance with earlier reports (Zhang and Piantadosi, 1994; Kil et al., 1996; Negishi et al., 2003).

Ischemic preconditioning before severe ischemia preserved the neuronal signal (Figure 2), suggesting that ischemic preconditioning induces ischemic tolerance in the animal models used in this study. An increased level of antioxidants is considered a critical step in the development of ischemic tolerance. For instance, ischemic preconditioning enhances synthesis of $\mathrm{Mn}-\mathrm{SOD}$ in the hippocampus (Kato et al., 1995; Stroev et al., 2004). Increased activity of Mn-SOD through ischemic preconditioning would cause increased production of hydrogen peroxide and subsequently hydroxyl radicals, through the Fenton reaction. Thus, in an animal that underwent preconditioning, the generation of hydroxyl radicals following subsequent severe ischemia would depend upon the activity of $\mathrm{H}_{2} \mathrm{O}_{2}$-degrading enzymes, including $\mathrm{GPx}$ and catalase. Thus, we determined whether ischemic preconditioning affects the levels of hydroxyl radicals during the severe ischemia-reperfusion period. Unexpectedly, our results showed that there was no significant difference between preconditioned and control groups in terms of the 2,3-DHBA levels during severe ischemia-reperfusion in the hippocampal CA1 area. However, since we only examined the hydroxyl radical levels for 120 min after reperfusion, we cannot rule out the possibility that hydroxyl radical concentrations differ in later phase of reperfusion between the two groups.

In both mature and neonatal brain, studies with GPx-1-overexpressing mice have shown significant neuroprotection against focal cerebral ischemia as well as hypoxia (Weisbrot-Lefkowitz et al., 1998; Furling et al., 2000; Ishibashi et al., 2002; Sheldon et al., 2004). Truelove et al. (1994) also provided evidence that microinfusion of catalase reduces neuronal damage following repetitive ischemic insult. Interestingly, our data indicates that the activity of GPx-1 and catalase is significantly increased in the hippocampus 3 days after ischemic preconditioning, although the level of protein expression does not increase concomitantly. This 
temporal pattern overlaps with the period during which ischemic preconditioning can provide protection against subsequent ischemia (Kato et al., 1994; Dooley and Corbett, 1998; Zhou et al., 2004). This suggests that the increase in GPx-1 and catalase activity induced by ischemic preconditioning may contribute to degrading hydrogen peroxide generated by subsequent severe ischemia-reperfusion. Considered together with results showing increased SOD activity in the ischemically preconditioned animals (Kato et al., 1995; Stroev et al., 2004), the increased rate of both synthesis and elimination of hydrogen peroxide after subsequent severe ischemia-reperfusion in preconditioned animals seems to be balanced, probably resulting in no significant change in hydroxyl radical levels in this situation.

It is known that levels of catalase and GPx activity do not necessarily correlate with protein expression (Brunelli et al., 2001; Sneddon et al., 2003; Drew et al., 2005). For example, nitric oxide can form a transient complex with resting catalase, thus reducing its activity. In addition, posttranslational modifications, such as phosphorylation, have been suggested to regulate GPx activity. $\mathrm{c}-\mathrm{Abl}$ and Arg tyrosine kinases phophorylate GPx1 on a tyrosine residue (Tyr-96), inhibiting its activity (Cao et al., 2003). Our data do not provide any evidence regarding the regulation of enzyme activities. Thus, further study is needed to determine the mechanisms by which antioxidant enzyme activity is enhanced by ischemic preconditioning.

In summary, our data suggests that the cooperative actions of antioxidant enzymes including catalase and GPx in the hippocampus after ischemic preconditioning reduce oxidative stress following severe ischemia and reperfusion, and play a role in the development of ischemic tolerance.

\section{Acknowledgement}

This work was supported by the Korea Science and Engineering Foundation (KOSEF) through the Cell Death Disease Research Center at The Catholic University of Korea (R13-2002-005-02002-0).

\section{References}

Brunelli L, Yermilov V, Beckman JS. Modulation of catalase peroxidatic and catalatic activity by nitric oxide. Free Radic Biol Med 2001;30:709-14

Calapai G, Crupi A, Firenzuoli F, Marciano MC, Squadrito F, Inferrera G, Parisi A, Rizzo A, Crisafulli C, Fiore A, Caputi AP. Neuroprotective effects of Ginkgo biloba extract in brain ischemia are mediated by inhibition of nitric oxide synthesis. Life Sci 2000;67:2673-83

Cao C, Leng Y, Huang W, Liu X, Kufe D. Glutathione peroxidase 1 is regulated by the c-Abl and Arg tyrosine kinases. J Biol Chem 2003;278:39609-14

Chan PH, Kawase M, Murakami K, Chen SF, Li Y, Calagui B, Reola L, Carlson E, Epstein CJ. Overexpression of SOD1 in transgenic rats protects vulnerable neurons against ischemic damage after global cerebral ischemia and reperfusion. J Neurosci 1998;18:8292-9

Choi YS, Yoon YH, Lee JE, Cho KO, Kim SY, Lee SB. Postischemic treatment with aminoguanidine inhibits peroxynitrite production in the rat hippocampus following transient forebrain ischemia. Kor J Physiol Pharmacol 2004;8:1-5

Christensen T, Bruhn T, Balchen T, Diemer NH. Evidence for formation of hydroxyl radicals during reperfusion after global cerebral ischaemia in rats using salicylate trapping and microdialysis. Neurobiol Dis 1994;1:131-8

Dooley P, Corbett D. Competing processes of cell death and recovery of function following ischemic preconditioning. Brain Res 1998;794:119-26

Drew JE, Arthur JR, Farquharson AJ, Russell WR, Morrice PC, Duthie GG. Salicylic acid modulates oxidative stress and glutathione peroxidase activity in the rat colon. Biochem Pharmacol 2005;70:888-93

Furling D, Ghribi O, Lahsaini A, Mirault ME, Massicotte G. Impairment of synaptic transmission by transient hypoxia in hippocampal slices: improved recovery in glutathione peroxidase transgenic mice. Proc Natl Acad Sci USA 2000;97:4351-6

Gutteridge JM. Ferrous ion-EDTA-stimulated phospholipid peroxidation. A reaction changing from alkoxyl-radical- to hydroxyl-radical-dependent initiation. Biochem J 1984;224: 697-701

Hayashi T, Saito A, Okuno S, Ferrand-Drake M, Dodd RL, Chan $\mathrm{PH}$. Damage to the endoplasmic reticulum and activation of apoptotic machinery by oxidative stress in ischemic neurons. J Cereb Blood Flow Metab 2005;25:41-53

Hicks CA, Ward MA, Swettenham JB, O'Neill MJ. Synergistic neuroprotective effects by combining an NMDA or AMPA receptor antagonist with nitric oxide synthase inhibitors in global cerebral ischaemia. Eur J Pharmacol 1999;381:113-9

Ingelman-Sundberg $\mathrm{M}$, Kaur $\mathrm{H}$, Terelius $\mathrm{Y}$, Persson JO, Halliwell $B$. Hydroxylation of salicylate by microsomal fractions and cytochrome P-450. Lack of production of 2,3-dihydroxybenzoate unless hydroxyl radical formation is permitted. Biochem J 1991;276:753-7

Ishibashi N, Prokopenko O, Weisbrot-Lefkowitz M, Reuhl $\mathrm{KR}$, Mirochnitchenko O. Glutathione peroxidase inhibits cell death and glial activation following experimental stroke. Mol Brain Res 2002;109:34-44

Kato $\mathrm{H}$, Kogure K, Liu Y, Araki T, Itoyama Y. Induction of $\mathrm{NADPH}$-diaphorase activity in the hippocampus in a rat model of cerebral ischemia and ischemic tolerance. Brain Res 1994;652:71-5 
Kato H, Kogure K, Araki T, Liu XH, Kato K, Itoyama Y. Immunohistochemical localization of superoxide dismutase in the hippocampus following ischemia in a gerbil model of ischemic tolerance. J Cereb Blood Flow Metab 1995;15:6070

Kil HY, Zhang J, Piantadosi CA. Brain temperature alters hydroxyl radical production during cerebral ischemia/ reperfusion in rats. J Cereb Blood Flow Metab 1996;16:100-6

Kim DH, Cho IH, Kim HS, Jung JE, Kim JE, Lee KH, Park T, Yang YM, Seong SY, Ye SK, Chung MH. Anti-inflammatory effects of 8-hydroxydeoxyguanosine in LPS-induced microglia activation: suppression of STAT3-mediated intercellular adhesion molecule-1 expression. Exp Mol Med 2006;38:417-27

Kim YH, Kim EY, Gwag BJ, Sohn S, Koh JY. Zinc-induced cortical neuronal death with features of apoptosis and necrosis: mediation by free radicals. Neuroscience 1999;89:175-82

Kitagawa K, Matsumoto M, Tagaya M, Hata R, Ueda H, Niinobe M, Handa N, Fukunaga R, Kimura K, Mikoshiba K, Kamada T. 'Ischemic tolerance' phenomenon found in the brain. Brain Res 1990;528:21-4

Lee MY, Choi YS, Choi JS, Min DS, Chun MH, Kim ON, Lee SB, Kim SY. An immunohistochemical study of APG-2 protein in the rat hippocampus after transient forebrain ischemia. Brain Res 2002;924:237-41

Negishi H, Ikeda K, Nara Y, Yamori Y. Estimation of hydroxyl radicals based on the salicylate trapping method in hippocampus of stroke-prone spontaneously hypertensive rats (SHRSP) during transient ischemia and recirculation. Adv Exp Med Biol 2003;510:313-7

Obata T. Use of microdialysis for in vivo monitoring of hydroxyl free radical generation in the rat. J Pharm Pharmacol 1997;49:724-30

Paxinos G, Watson C. The Rat Brain in Stereotaxic Coordinates, 4th Ed, 1998, Academic Press, New York, USA

Piantadosi CA, Zhang J. Mitochondrial generation of reactive oxygen species after brain ischemia in the rat. Stroke 1996;27:327-31

Pulsinelli WA, Brierley JB. A new model of bilateral hemispheric ischemia in the unanesthetized rat. Stroke 1979;10: 267-72

Rollet-Labelle E, Grange MJ, Elbim C, Marquetty C, Gougerot-Pocidalo MA, Pasquier C. Hydroxyl radical as a potential intracellular mediator of polymorphonuclear neutrophil apoptosis. Free Radic Biol Med 1998;24:563-72

Sheldon RA, Jiang X, Francisco C, Christen S, Vexler ZS, Tauber MG, Ferriero DM. Manipulation of antioxidant pathways in neonatal murine brain. Pediatr Res 2004;56: 656-62

Sneddon AA, Wu HC, Farquharson A, Grant I, Arthur JR, Rotondo D, Choe SN, Wahle KW. Regulation of selenoprotein GPx4 expression and activity in human endothelial cells by fatty acids, cytokines and antioxidants. Athero- sclerosis 2003;171:57-65

Song HY, Ryu J, Ju SM, Park LJ, Lee JA, Choi SY, Park J. Extracellular HIV-1 Tat enhances monocyte adhesion by up-regulation of ICAM-1 and VCAM-1 gene expression via ROS-dependent NF-кB activation in astrocytes. Exp Mol Med 2007;39:27-37

Stroev SA, Gluschenko TS, Tjulkova El, Spyrou G, Rybnikova EA, Samoilov MO, Pelto-Huikko M. Preconditioning enhances the expression of mitochondrial antioxidant thioredoxin-2 in the forebrain of rats exposed to severe hypobaric hypoxia. J Neurosci Res 2004;78:563-9

Sugawara T, Noshita N, Lewen A, Gasche Y, Ferrand-Drake M, Fujimura M, Morita-Fujimura Y, Chan PH. Overexpression of copper/zinc superoxide dismutase in transgenic rats protects vulnerable neurons against ischemic damage by blocking the mitochondrial pathway of caspase activation. J Neurosci 2002;22:209-17

Sugawara T, Kinouchi H, Oda M, Shoji H, Omae T, Mizoi K. Candesartan reduces superoxide production after global cerebral ischemia. Neuroreport 2005;16:325-8

Troy CM, Derossi D, Prochiantz A, Greene LA, Shelanski ML. Downregulation of $\mathrm{Cu} / \mathrm{Zn}$ superoxide dismutase leads to cell death via the nitric oxide-peroxynitrite pathway. J Neurosci 1996;16:253-61

Truelove D, Shuaib A, ljaz S, Richardson S, Kalra J. Superoxide dismutase, catalase, and U78517F attenuate neuronal damage in gerbils with repeated brief ischemic insults. Neurochem Res 1994;19:665-71

Tsang SY, Tam SC, Bremner I, Burkitt MJ. Copper1,10-phenanthroline induces internucleosomal DNA fragmentation in HepG2 cells, resulting from direct oxidation by the hydroxyl radical. Biochem J 1996;317:13-6

Wada K, Miyazawa T, Nomura N, Tsuzuki N, Nawashiro H, Shima K. Preferential conditions for and possible mechanisms of induction of ischemic tolerance by repeated hyperbaric oxygenation in gerbil hippocampus. Neurosurgery 2001;49:160-6

Weisbrot-Lefkowitz M, Reuhl K, Perry B, Chan PH, Inouye $\mathrm{M}$, Mirochnitchenko O. Overexpression of human glutathione peroxidase protects transgenic mice against focal cerebral ischemia/reperfusion damage. Mol Brain Res 1998;53:333-8

Yamamoto T, Yuki S, Watanabe T, Mitsuka M, Saito KI, Kogure K. Delayed neuronal death prevented by inhibition of increased hydroxyl radical formation in a transient cerebral ischemia. Brain Res 1997;762:240-2

Zhang J, Piantadosi CA. Prolonged production of hydroxyl radical in rat hippocampus after brain ischemia-reperfusion is decreased by 21-aminosteroids. Neurosci Lett 1994;177: $127-30$

Zhou AM, Li WB, Li QJ, Liu HQ, Feng RF, Zhao HG. A short cerebral ischemic preconditioning up-regulates adenosine receptors in the hippocampal CA1 region of rats. Neurosci Res 2004;48:397-404 